\title{
ACCOMMODATION VERSUS CONTROL SUGGESTED MODEL TO MACRO-ECONOMICS
}

\author{
Yassin Eltahir ${ }^{1}$ \\ date of paper receipt: \\ date of sending to review: \\ date of review receipt: \\ 05.04.2019. \\ 08.04.2019. \\ 19.04.2019. \\ Review Article \\ doi: 10.2478/eoik-2019-0009 \\ UDK: $330.101 .54: 338.488 .2$ \\ ${ }^{1}$ College of Business-King Khalid University KSA, Saudi Arabia
}

\begin{abstract}
The study raised the question of knowledge generation, in attempt to answer this question an economic model was introduced, namely, aggregate demand and aggregate supply. The final target equations can be solved by general rule (deterministic) of solving quadratic equations. The study use analytical geometry and matrix algebra tools to solve the model beside testing their stability characteristics. If we reach unique value to the price equilibrium level then income equilibrium level the maximum potency of the economy can determined. Accordingly the rest of model values would be solved spontaneously. The essential derived result is the relationship between the dependent variable and independent variable can be redefined into accommodated and accommodator one. The long run growth rate of price and income which equal to the equilibrium combat with exogenous theory of growth which seeking stable and sustainable growth. Other results center around how to view the debate of different economic schools from the shape of aggregate demand and aggregate supply, moreover the theoretical and practical test of model give great push to the suggested approach in answering the questions raised concerning the knowledge generation. If the model succeed in exceeding the theoretical and practical tests our understanding to the phenomena functioning will be broaden and enhanced, hence the model capability can be enlarged to interpret phenomena in fields other than economic, typically the suggested approach “ top to bottom" may contribute positively to the process of knowledge generation in addition to the modification of value system extraction. Finally the study suggested a protocol scenario in how to apply the derived model by introducing different steps to the application.
\end{abstract}

Keywords:

aggregate demand, aggregate supply, Accommodation, Control 


\section{INTRODUCTION}

We started the study by raising the following question; is the independent variables are true independence to influence the phenomena under study? Or is there exist enough freedom to the independent variables to orient the dependent variable toward the desired direction. So the main point behind the study is to examine to what extent that the independent variables has limited role in influencing the dependent variables, such examining would clarify the starting point though which we can viewing the problem under study. So if the phenomena is fully subject to outside factor the hypothesis is rejected which stated self-independency of the phenomena under study (ad hoc variable). To tackle such task we revert to macroeconomics models by relaxing them in a purpose of conducting such suggested approach which emphasis on latent independency of each phenomena in reposing to outside factors. Such latent independency compels the outside factors to readjust them self to accommodate the pre-choice of the phenomena.

This suggested model is opposes to what so called the control model which attempts to reach targets through modifying the path of dependent variable by controlling the first roots of the problem under study, accordingly the objectives of the study are:-

- Introducing a method center around latent independency of ad hoc variable.

- Determining the maximum potency which the dependent variable can reach

- Explaining the role of independent variable in accelerating this path (maximum potency)

These aims can be achieved if the theoretical and practical tests to the model reveal its strengthening why freedom is less persisted in the independent variables. Moreover if the model provided accurate interpretation to economic situation via looking to the phenomena from top to bottom in a sense that the maximum potency that phenomena can reach will motivate the independent variables to actively perform it i.e the independent variables pave the way to the dependent variable to accomplish its maximum potency.

The importance of the model stems from its stable characteristic which relates the maximum potency level to long run growth level which satisfies the requirements of long run dynamic stability. The significance of the study based on the ability of the model in explaining the phenomena from top to bottom which may contribute in the debate concerning stability in contrast to viewing stability by controlling the dependent variable.

If the above concerns are fully demonstrated field outside economic can apply the modification version of the approach in suiting their problems peculiarities by using the same procedures . Hence the findings may consolidate or criticize the applications of the model.

To explore and describe things nature it is importance to use proper and accurate knowledge. So the way of using the knowledge, to larger extent, pave the ground toward smooth and easy life. In addition the benevolence values in the life are derived from knowledge generation and hence spill over all aspects of life. Many challenges face the process of knowledge i.e does the available methods are satisfactory to answer all questions faced the human being or much need exist to develop our methods in order to facilitate the matter. Generation of knowledge is more essential process in dealing with the phenomena under study. The ongoing efforts attempt to control the phenomenal and then orient them to coup with the policy makers aims. In this concern the way of generation knowledge define the pole of how things functioning either one way causation or how ways causation, accordingly the phenomena under study is considerably control and manage.

This study attempts to address new concerns with regard to knowledge generation and the respective repercussions follow it. The functioning mechanism which driving the knowledge through controlling approaches is it satisfactory and appropriate?. Accordingly the main question of the study centered around whether controlling the phenomena is only version for tackling it? Or in other word does there exist other version dealing with the phenomena in same way as controlling approach?. The sub questions of the study are; what are the features of the suggested approach? Also does the suggested approach offer satisfactory answers to questions facing the phenomena 
under the study? Moreover does the suggested approach is testable and applicable.

The study aims at contribution in enriching the literature concerning the knowledge generation, beside attempt to introduce approach dealing with broader description and analysis of phenomenal , moreover the study aims at display how the new approach integrated in reflecting the mutual causation between the dependent and independent variables of the phenomena under study. The importance of the study stems from how the suggested approach raises genuine questions associate with managing and accommodating the phenomena. The methodological technique used in this study is microeconomics model, particularly aggregate demand and aggregate supply. Here new derivation to equation were to be postulated then new approach can be formed.

\section{LITERATURE REVIEW}

Sherstnev (2019) World Economy, Economic Science, and Economic Policy: What Comes After the Crisis. In this research he discussed he was demonstrated that that global economic crisis showed the limited ability of mainstream in economics, primarily in new macroeconomics and financial economics, hence, the attention of researchers and economic policy-makers was drawn again to some alternative views in economics

Dopp,etal (2019) Mixed-method approaches to strengthen economic evaluations in implementation research. This paper focused on the emergence of qualitative methods for economic evaluation which offers a promising solution. So it recommend that researchers embrace a mixed-methods research agenda that merges traditional quantitative approaches with innovative, contextually grounded qualitative methods.

Arestis, (2018) Keynesian macroeconomic policy: Theoretical analysis and empirical evidence. This research emphasized on macroeconomic policies which have capabilities of affecting effective demand and building a good institutional environment, which develop a Keynesian type of macroeconomic policy able to stimulate investment and effective demand.

Colander (2011) Is the fundamental science of macroeconomics sound.The concerns of this paper is that Bernanke is wrong and that standard macroeconomics has not recognized, and still does not recognize, the limits of science and of formal modeling when studying something as complex as the macro economy. This failure to recognize, and adequately convey to policy makers, the limits of our scientific understanding of the macro economy So the study advocates a classical methodological approach, which Keynes followed as well, that strictly separates fundamental science from policy analysis. Policy does not directly follow from models; it follows from reasoned analysis which uses models.

Halsmayer, eatal ,(2016) Solow's Harrod: Transforming macroeconomic dynamics into a model of long-run growth, this study focuses onModern growth theory of growth derives mostly from Solow's which tend toward progressive deterioration of the economy. providing a "dynamic" theory had little to do with the problem of long-run growth, but instead addressed medium-run fluctuations, the "inherent instability" of economies. Solow's version, which dominated by the difficulties in communicating across distinct interpretive communities .

The above studies focus in different area in macroeconomic which are mathematical modeling, growth, stability, school debate as well as macroeconomics modeling. The suggested study introduces mathematical macroeconomic model which bear in mind almost the questions raised by above mentioned studies in manner that tackle the problem in different way.

\section{KNOWLEDGE GENARATION}

The way in which phenomena are viewed is considered to be an input to the understanding of phenomena. Through these approaches it is possible to generate and discover knowledge and then to create and inboded it into human behavior according to the rules of knowledge generation. 
According to the method of generating knowledge, the variables are classified as ad hoc or post hoc. In this study, we will address the method of controlling or controlling variables and compare it to the proposed approach, which is accommodation according to the macroeconomic model derived in the study.

The study is trying to answer the question of whether the functional relations of studying of phenomena enough to understand the phenomenon and predict the future. Or rather does the ad hoc variables able to direct the phenomenon to any path they want or the phenomena has some degree of self-independence. Based on the answer to this question will be illuminated aspects of the question of what is the degree of certainty that we have in knowing the phenomenon under study The methodology used in the study is to derive a macro-economic model using the theory of national income which is the most important macroeconomic indicator. According to the test of the model and its feasibility, it is possible to answer the study questions, as well as to derive the cognitive and value-based results of the model. Finally, it will be proposed to apply in other areas or the future horizon of the approach.

\section{CONTROL}

This method looks at the so-called ad hoc variables, independent or priori to understand the phenomenon through the study of the smallest unit or the first root in the phenomenon as the main engine of the phenomenon. This assumption consider the first root as starting point of the phenomenon or the first component. Accordingly studying and understanding the first root of the phenomenon leads to give a reasonable view to comprehend the way the phenomenon works and thus can be controlled by the movement of the ad hoc or independent variables. For example, the phenomenon of life it's the root is the cell, the substance its first atom and in the economy the first roots of economic activity are utility and profit. These first roots are thought to be governing and motivating these phenomena. Understanding the way these roots work leads to the understanding of phenomena and directing them through the principle of free first root.

Following this approach led to remarkable results in the field of exact and human sciences by searching for the first root of the phenomenon and then understanding and guiding the phenomenon through the principle of freedom of the first root or the first component of the phenomenon under study.

\section{ACCOMMODATION}

This method assumes that the phenomenon has a maximum limit (potency)of response which allows the ad hoc variables to move the phenomenon towards it. The maximum extent of the phenomenon can be deduced through the interaction of opposing forces that form phenomena. This potency is constant and moving from time to time and can increase or decrease. In this case, the ad hoc variables will be accommodators to the phenomenon and will only work to achieve such potency or limit. Any attempt to control the phenomenon and guide it away from this ultimate path leads to a complete disturbance in the system. This approach assumes that there is a kind of self-tendency of the phenomena towards a definite end from time to time and thus attempting to dispel the phenomenon from this tendency of reorientation may not succeed in reaching the desired target. The result of this method is that the absolute freedom of the ad hoc variables to guide the phenomenon is uncertain and may only result from directing the phenomenon if the process of directing the path is in line with the subjective tendency of the phenomenon towards a particular destination. Thus, the ad hoc variables become accommodators and their function only to help the phenomenon in reaching its maximum capacity. Freedom here is subject to or conditional to compatibility with the path of phenomenon, whether incremental or decreasing. 


\section{THE MODEL}

This study uses the macroeconomic theory to examine and test the accommodation versus control. The model used is the study and analysis of income as the most important indicator in the economic through the approach of aggregate demand and supply as contradicting forces contribute to understanding the phenomenon of income and determine the maximum potency of the economy, then determining of the size of income and its path from time to time. The model is based on the mathematical derivation of the income equilibrium using four sectors (product-money-laborforeign exchange). From the equations introduced in the model we conclude with two equations, one for aggregate demand and the other for aggregate supply, by solving them using quadratic equation factorization we can reach the equilibrium level of income and prices. This equilibrium point determines the maximum potency economy that the ad hoc variables can accelerate its reach. This situation can lead to a recession or prosperity that may be unavoidable by using ad hoc variables in directing the phenomena.

This method proposes to solve the system from top to bottom, which begins by determining the size and the position of the maximum potency and then choose the values of the first roots that achieve this status or the maximum potency of the phenomenon. This is different from the first method, which looks from the bottom to the top by determining the values of the first roots that direct the phenomenon towards the goal desired. Using the accommodation method that works from top to bottom, the ad hoc variables are the servant of the phenomenon and not orient it because all the values of the first roots within the system are determined according to the equilibrium which is maximum potency of the phenomenon or its tendency towards a specific path. In this case, the ad hoc variables work for the phenomenon to serve its own plan or path rather than directing it. In other words, the accommodator meets the desires and aspirations of the accommodated.

of IS curve (Product market)

G $(1)$

Government expenditure ( Constant)

$$
I=d-e i+v y
$$

Investment

where;

$$
\begin{gathered}
\mathrm{I} \equiv \text { Investment } \\
\mathrm{d} \equiv \text { Constant } \\
\mathrm{e} \equiv \text { Elasticity of investment for interest rate } \\
\mathrm{i} \equiv \text { Interest rate } \\
v \equiv \text { Accelerator coefficient } \\
\mathrm{S}=-\mathrm{a}+\mathrm{sY}-\Delta \mathrm{Y}_{\mathrm{t}-\mathrm{l}} \\
\text { Saving } \quad \text { where; }
\end{gathered}
$$




$$
\begin{aligned}
& \mathrm{S} \equiv \text { Saving } \\
& \mathrm{a} \equiv \text { Constant } \\
& \mathrm{s} \equiv \text { Marginal propensity to save } \\
& \mathrm{Y} \equiv \text { Income } \\
& \mathrm{Y}_{\mathrm{t}-1} \equiv \text { lag income } \\
& \Delta \equiv \text { growth rate of income } \\
& \mathrm{Y}=\Theta+\Omega \mathrm{Y}_{\mathrm{t}-1} \\
& \mathrm{Y}_{\mathrm{t}-1}=\frac{Y}{\Omega}-\frac{\Theta}{\Omega} \\
& \mathrm{S}=-\mathrm{a}+\mathrm{sY}-\Delta\left[\frac{\mathrm{Y}}{\Omega}-\frac{\Theta}{\Omega}\right] \\
& \mathrm{S}=-\mathrm{a}+\mathrm{sY}-\frac{\Delta \mathrm{Y}}{\Omega}+\frac{\Delta \Theta}{\Omega} \\
& \mathrm{S}=-\mathrm{a}+\left[\mathrm{s}-\frac{\Delta}{\Omega}\right] \mathrm{Y}+\frac{\Delta \Theta}{\Omega} \\
& T=t_{0}+t Y \\
& \mathrm{~T} \equiv \text { Total tax } \\
& \mathrm{t}_{0} \equiv \text { Indirect tax } \\
& \mathrm{t} \equiv \text { Direct tax rate } \\
& \mathrm{Y} \equiv \text { Income }
\end{aligned}
$$

IS curve is derived by the following rule:-

$$
I+G=S+T
$$

By substituting equations (1) to (4) in rule (5) we get

$$
\begin{gathered}
\mathrm{G}+\mathrm{d}-\mathrm{ei}+v y=-\mathrm{a}+\left[\mathrm{s}-\frac{\Delta}{\Omega}\right] \mathrm{Y}+\frac{\Delta \Theta}{\Omega}+t_{0}+t Y \\
\left(\mathrm{G}+\mathrm{d}+\mathrm{a}-\frac{\Delta}{\Omega} \Theta-\mathrm{t}_{0}\right)-\mathrm{ei}=\left(\mathrm{s}-\frac{\Delta}{\Omega}-v+t\right) \mathrm{Y} \\
\frac{\left[\mathrm{G}+\mathrm{d}+\mathrm{a}-\frac{\Delta}{\Omega} \Theta-\mathrm{t} 0\right]}{\left[\mathrm{s}-\frac{\Delta}{\Omega}-v+t\right]}-\left[\frac{e}{\mathrm{~s}-\frac{\Delta}{\Omega}-v+t}\right] i=\mathrm{Y}
\end{gathered}
$$

Algebra of (LM) curve (Money Market) 


$$
M^{d}=f-h i+k y
$$

Demand for money

where;

$\equiv$ Demand for money $\mathrm{M}^{\mathrm{d}}$

$$
\mathrm{f} \equiv \text { Constant }
$$

$\mathrm{h} \equiv$ demand for money elasticity for interest rate

$$
\mathrm{I} \equiv \text { Interest rate }
$$

$\mathrm{k} \equiv$ Percentage of income in form of money

$$
\mathrm{Y} \equiv \text { Income }
$$

$$
M^{s}=n+c i-j p
$$

Supply of money

Where;

$$
\begin{aligned}
\mathrm{M}^{\mathrm{s}} & \equiv \text { Money supply } \\
\mathrm{n} & \equiv \text { Constant }
\end{aligned}
$$

$c \equiv$ Supply of money elasticity for interest rate

$$
\mathrm{I} \equiv \text { Interest rate }
$$

$\mathrm{j} \equiv$ Supply of money elasticity for price level

$$
\mathrm{p} \equiv \text { Price level }
$$

(LM) curve is derived by the following rule:-

$$
M^{d}=M^{s}
$$

By substituting equations (7) and (8) in rule (9) we get

$$
\begin{array}{r}
f-h i+k y=n+c i-j p \\
k y=n-f+h i+c i-j p \\
y=\left(\frac{n-f}{k}\right)+\left(\frac{h+c}{k}\right) i-\left(\frac{j}{c}\right) p
\end{array}
$$

By assuming fixed price level, from equation $(10)$ the term $(\mathrm{j} / \mathrm{c})$ equal zero therefore (LM) cure only function in interest rate

$$
y=\left(\frac{n-f}{k}\right)+\left(\frac{h+c}{k}\right) i
$$




\section{Derivation of $(\mathrm{AD})$ curve:-}

Aggregate demand is a relation between income and price level and is derived from the equilibrium of product market and money market. The adaptation with price level happens in money market equation (10). As far as equilibrium level of interest rate is get from product market, IS curve, equation (6) as follows:-

$$
\mathrm{I}=\frac{\left[\mathrm{G}+\mathrm{d}+\mathrm{a}-\frac{\Delta}{\Omega} \Theta-\mathrm{t} 0\right]}{e}-\left[\frac{\mathrm{s}-\frac{\Delta}{\Omega}-v+t}{e}\right] \mathrm{Y}
$$

By substituting equation (12) in equation (10) we get:-

$$
\mathrm{Y}=\left(\frac{n-f}{k}\right)+\left(\frac{h+c}{k}\right)\left[\left(\frac{\mathrm{G}+\mathrm{d}+\mathrm{a}-\frac{\Delta}{\Omega} \Theta-\mathrm{t} 0}{e}\right)-\left[\frac{\mathrm{s}-\frac{\Delta}{\Omega}-v+t}{e}\right] Y\right]-\left(\frac{j}{c}\right) p
$$

By tracing the derivation we get aggregate demand curve from equation (13) in its final form as follows:-

$$
\begin{gathered}
\mathrm{Y}=\left(\frac{n-f}{k}\right)+\frac{(h+c)\left(\mathrm{G}+\mathrm{d}+\mathrm{a}-\frac{\Delta}{\Omega} \Theta-\mathrm{t} 0\right)}{k e}-\left(\frac{h+c)}{k}\right)\left[\frac{\mathrm{s}-\frac{\Delta}{\Omega}-v+t}{e}\right] Y-\left(\frac{j}{c}\right) p \\
\mathrm{Y}\left[1+\frac{(h+c)\left(\mathrm{s}-\frac{\Delta}{\Omega}-v+t\right)}{k e}\right]=\left(\frac{n-f}{k}\right)+\frac{(h+c)\left(\mathrm{G}+\mathrm{d}+\mathrm{a}-\frac{\Delta}{\Omega} \Theta-\mathrm{t} 0\right)}{k e}-\left(\frac{j}{c}\right) p \\
\mathrm{Y}=\left[\left(\frac{n-f}{k}\right)+\frac{(h+c)\left(\mathrm{G}+\mathrm{d}+\mathrm{a}-\frac{\Delta}{\Omega} \Theta-\mathrm{t} 0\right)}{k e}\right]\left[\frac{1}{\left(1+\frac{(h+c)\left(\mathrm{s}-\frac{\Delta}{\Omega}-v+t\right)}{k e}\right)}\right]- \\
\left(\frac{j}{c}\right)\left[\frac{1}{\left(1+\frac{(h+c)\left(\mathrm{s}-\frac{\Delta}{\Omega}-v+t\right)}{k e}\right)}\right] p
\end{gathered}
$$

Extension to open economy:

In this state we add the foreign exchange market in order to count the effect of international exchange. Here we add export plus capital inflow as a demand side and import plus capital outflow as a supply side. Then we subtract supply from demand and hence the final result is foreign exchange surplus. We this surplus (in term of prices level and interest rate) to the aggregate demand equation in hope of derivation the final equation of aggregate demand with the effect of international exchange.

The equations of foreign exchange market:-

Export

$$
X=\sigma-\delta P+\varepsilon Y-\phi E
$$

Where; 


$$
\begin{gathered}
\mathrm{X} \equiv \text { export } \\
\sigma \equiv \text { constant } \\
\delta \equiv \text { elasticity of export for prices level } \\
\varepsilon \equiv \text { elasticity of export for income } \\
\phi \equiv \text { elasticity of export for exchange rate } \\
\text { Import } \\
M=\theta+\rho P+\mu Y+\chi E
\end{gathered}
$$

Where;

$$
\begin{aligned}
& M \equiv \text { Import } \\
& \theta \equiv \text { constant }
\end{aligned}
$$$$
\rho \equiv \text { elasticity of import for prices level }
$$$$
\mu \equiv \text { elasticity of import for income }
$$$$
\chi \equiv \text { elasticity of import for exchange rate }
$$$$
\text { Capital inflow }
$$$$
C_{\text {inf }}=M+\psi i
$$

Where;

$$
\begin{gathered}
\mathrm{C}_{\mathrm{inf}} \equiv \text { capital inflow } \\
\mathrm{m} \equiv \text { constant }
\end{gathered}
$$

$\psi \equiv$ elasticity of capital inflow for interest rate

Capital outflow

$$
C_{\text {outf }}=N-\varpi i
$$

Where;

$$
\begin{gathered}
\mathrm{C}_{\text {outf }} \equiv \text { capital outflow } \\
\mathrm{n} \equiv \text { constant }
\end{gathered}
$$

$\varpi \equiv$ elasticity of capital outflow for interest rate

In order to put the equations of the foreign exchange market only in term of prices level and interest rate we treat exchange rate in term of interest rate as follows:- 
Exchange rate

$$
E=\varphi+\eta I
$$

Where;

$$
\begin{gathered}
E \equiv \text { exchange rate } \\
\varphi \equiv \text { constant }
\end{gathered}
$$

$\eta \equiv$ elasticity of exchange rate for interest rate

$$
\equiv \text { interest rate } I
$$

The foreign exchange market is;

$$
\begin{gathered}
(\sigma-\delta P+\varepsilon Y-\phi E+M+\psi i)-(\theta+\rho P+\mu Y+\chi E+N-\varpi i) \\
(\sigma-\theta)-(\delta+\rho) P+(\varepsilon-\mu) Y-(\phi-\chi) E+(m+n)+(\psi-\varpi) i \\
(\sigma-\theta)-(\delta+\rho) P+(\varepsilon-\mu) Y-(\phi-\chi)[\varphi-\eta I]+m+n+(\psi-\varpi) i \\
(\sigma-\theta)-(\delta+\rho) P+(\varepsilon-\mu) Y-\phi \varphi+\chi \varphi+(m+n)+[\phi-\chi] \eta I+(\psi-\varpi) i \\
(\sigma-\theta)-(\delta+\rho) P+(\varepsilon-\mu) Y-\phi \varphi+\chi \varphi+(m+n)+[(\phi-\chi) \eta+(\psi-\varpi)] i
\end{gathered}
$$

From equation (12) the interest rate is;

$$
\mathrm{I}=\frac{\left[\mathrm{G}+\mathrm{d}+\mathrm{a}-\frac{\Delta}{\Omega} \Theta-\mathrm{t} 0\right]}{e}-\left[\frac{\mathrm{s}-\frac{\Delta}{\Omega}-v+t}{e}\right] \mathrm{Y}
$$

The foreign exchange surplus only in term of prices level and interest rate is;

$$
\begin{gathered}
(\sigma-\theta)-(\delta+\rho) P+(\varepsilon-\mu) Y-\phi \varphi+\chi \varphi+(m+n)+[(\phi-\chi) \eta+(\psi-\varpi)] \\
{\left[\frac{\left[\mathrm{G}+\mathrm{d}+\mathrm{a}-\frac{\Delta}{\Omega} \Theta-\mathrm{t} 0\right]}{e}-\left[\frac{\mathrm{s}-\frac{\Delta}{\Omega}-v+t}{e}\right] \mathrm{Y}\right]}
\end{gathered}
$$

We add the surplus to the equation (14)

$$
\begin{gathered}
\mathrm{Y}=\left[\left(\frac{n-f}{k}\right)+\frac{(h+c)\left(\mathrm{G}+\mathrm{d}+\mathrm{a}-\frac{\Delta}{\Omega} \Theta-\mathrm{t} 0\right)}{k e}\right]\left[\frac{1}{\left(1+\frac{(h+c)\left(\mathrm{s}-\frac{\Delta}{\Omega}-v+t\right)}{k e}\right)}\right]-\left(\frac{j}{c}\right)\left[\frac{1}{\left(1+\frac{(h+c)\left(\mathrm{s}-\frac{\Delta}{\Omega}-v+t\right)}{k e}\right)}\right] p+ \\
(\sigma-\theta)-(\delta+\rho) P+(\varepsilon-\mu) Y-\phi \varphi+\chi \varphi+(m+n)+[(\phi-\chi) \eta+(\psi-\varpi)] \\
{\left[\frac{\left[\mathrm{G}+\mathrm{d}+\mathrm{a}-\frac{\Delta}{\Omega} \Theta-\mathrm{t} 0\right]}{e}-\left[\frac{\mathrm{s}-\frac{\Delta}{\Omega}-v+t}{e}\right] \mathrm{Y}\right]}
\end{gathered}
$$




$$
\begin{aligned}
\mathrm{Y}\left[1+\left((\psi-\varpi)\left[\frac{\mathrm{s}-\frac{\Delta}{\Omega}-v+t}{e}\right]\right)\right]= & {\left[\left(\frac{n-f}{k}\right)+\frac{(h+c)\left(\mathrm{G}+\mathrm{d}+\mathrm{a}-\frac{\Delta}{\Omega} \Theta-\mathrm{t} 0\right)}{k e}\right]\left[\frac{1}{\left(1+\frac{(h+c)\left(\mathrm{s}-\frac{\Delta}{\Omega}-v+t\right)}{k e}\right)}\right]-} \\
& \left(\frac{j}{c}\right)\left[\frac{1}{\left(1+\frac{(h+c)\left(\mathrm{s}-\frac{\Delta}{\Omega}-v+t\right)}{k e}\right)}\right] p+
\end{aligned}
$$$$
(\sigma-\theta)-(\delta+\rho) P+(\varepsilon-\mu) Y-\phi \varphi+\chi \varphi+(m+n)+[(\phi-\chi) \eta+(\psi-\varpi)] \frac{\left[\mathrm{G}+\mathrm{d}+\mathrm{a}-\frac{\Delta}{\Omega} \Theta-\mathrm{t} 0\right]}{e}
$$

The final equation of aggregate demand is;

$$
\begin{aligned}
& \mathrm{Y}=\frac{1}{\left[1+\left((\psi-\varpi)\left[\frac{\mathrm{s}-\frac{\Delta}{\Omega^{-}}-t+t}{e}\right]\right)\right]}\left[\left[\left(\frac{n-f}{k}\right)+\frac{(h+c)\left(\mathrm{G}+\mathrm{d}+\mathrm{a}-\frac{\Delta}{\Omega} \Theta-\mathrm{t} 0\right)}{k e}\right]\left[\frac{1}{\left(1+\frac{(h+c)\left(\mathrm{s}-\frac{\Delta}{\Omega}-v+t\right)}{k e}\right)}\right]+\right. \\
& \left.(\sigma-\theta)-(\delta+\rho) P+(\varepsilon-\mu) Y-\phi \varphi+\chi \varphi+(m+n)+[(\phi-\chi) \eta+(\psi-\varpi)] \frac{\left[\mathrm{G}+\mathrm{d}+\mathrm{a}-\frac{\Delta}{\Omega} \Theta-\mathrm{t} 0\right]}{e}\right] \\
& -\left(\frac{j}{c}\right)\left(\frac{1}{\left[1+\left((\psi-\varpi)\left[\frac{s-\frac{\Delta}{\Omega}-v+t}{e}\right]\right)\right]}\right)\left[\frac{1}{\left(1+\frac{(h+c)\left(s-\frac{\Delta}{\Omega}-v+t\right)}{k e}\right)}\right] p \\
& \text { Derivation of (AS) curve:- } \\
& L^{d}=o-z \omega
\end{aligned}
$$

Demand for labour

where;

$$
\begin{gathered}
\mathrm{L}^{\mathrm{d}} \equiv \text { Demand for labour } \\
\mathrm{O} \equiv \text { constant } \\
\mathrm{z} \equiv \text { labour demand elasticity for wage } \\
\omega \equiv \text { real wage }
\end{gathered}
$$

Nominal wage curve is (Hyperbola) one of its properties is:-

$$
\omega=\left(\frac{x}{p}+\frac{\partial}{P t-1}\right)
$$

Where;

$p \equiv$ Price level 


$$
\begin{gathered}
\omega \equiv \text { Real wage } \\
\mathrm{x} \equiv \text { Constant } \\
\mathrm{P}_{\mathrm{t}-1} \equiv \text { lag of price level } \\
\partial \equiv \text { growth level of price } \\
\mathrm{P}={ }^{\oplus} \mathrm{P}_{\mathrm{t}-1} \quad \text { long run relation } \\
\mathrm{P}_{\mathrm{t}-1}=\left(\frac{\mathrm{P}}{\circledR}\right) \\
\mathrm{W}=\left(\frac{x}{p}-\frac{\partial \circledast}{p}\right) \\
\mathrm{W}=\left(\frac{1}{p}\right)[x-\partial \circledast]
\end{gathered}
$$

By substituting equation (17) in equation (15) we get the equilibrium quantity of labour as follows:-

$$
\mathrm{L}^{*}=\mathrm{o}-\left(\frac{z}{p}\right)[x-\partial 囚]
$$

The production function if capital and technological state are fixed is:-

$$
\begin{gathered}
y=\alpha+\lambda L^{*} \underset{\text { Where; }}{(24)} \\
y \equiv \text { Income } \\
\alpha \equiv \text { Constant count for capital and technological state } \\
\lambda \equiv \text { Coefficient of labour } \\
\mathrm{L}^{*} \equiv \text { Equilibrium labour quantity }
\end{gathered}
$$

By substituting equation (23) in equation (24) we get aggregate supply curve (AS) as follows:-

$$
\begin{array}{r}
\mathrm{Y}=\alpha+\lambda\left[0-\left(\frac{z}{p}\right)[x-\partial 囚]\right] \\
\mathrm{Y}=\alpha+\lambda \mathrm{o}-\left(\frac{1}{P}\right)[\lambda z x-\lambda z \partial 囚]
\end{array}
$$

As the aggregate supply function in prices level, we notice that the prices level in equation (25) in form of $(1 / p)$, therefore the product of subtraction is positive and hence the relationship between the prices level and income is direct despite the negative sign in the right side.

By solving equation (20) aggregate demand and equation (25) aggregate supply for equilibrium (second order equation for price level) we will find the equilibrium level of income (Y), after that the rest of the system vales will be deter 


\section{MODEL TEST}

Two tests to validate and apply the model are theoretical and practical. For theoretical testing, we examine the extent to which growth rates coincided to equilibrium rate for income and prices. The growth rate is measured by the value of the coefficients of the lag variables for the income and the prices and then comparing with the equilibrium achieved by solving the model which is a second-order equation, as shown by the final equations of the model (aggregate demand equation and aggregate supply equation). If the model passes the theoretical test, it is possible to go to the practical test, which is the study of historical data. If the historical data prove that the phenomenon of income and prices deviated from the plan of the ad hoc variables in case of incompatibility with phenomena maximum potency or on the other hand the phenomena moved in the same direction of ad hoc variables if the plan of ad hoc variables similar to the phenomenon path. In this case, it can be said that the model has historical evidence support its validity and interpretation.

To know the properties and characteristics of model we can forming square matrix (7.7) in seven dependent variables which are income, consumption, tax ,investment, demand of money, exports and imports. Each variable is subject to six independent variables which are government expenditure, tax , lag of income, money supply, price level, exchange rate beside the constant term. From this matrix characteristic equation can be form along with calculating eign values, eign vectors and eign space to check the degree of model stability.

If the historical test evidence gives a broader understanding of the phenomenon using the topbottom approach of accommodation or interpretation, it is safe to assume that the phenomena have self-tendency toward a specific path or potency and that cannot be overcome. The validity of the previous assumption is that the ability of the ad hoc variables to interpret the phenomena is conditional and limited and therefore cannot reverse, but only accelerate the path.

\section{RESULTS}

- The model is solve from top to bottom, when the equilibrium levels of income and price are determined the rest of the model values would be determined i.e the equilibrium values of price and income reflect the maximum potency of economy that can be reached running any type of policy.

- The roots variables (independent)functioning as accommodators to the dependent variable (accommodated) they drive the phenomena to reach its self-destination i.e the phenomena has self-inclination toward given target or end. Any attempt from the independent variables to drive it, according to study assumptions, would be failed or resulted in undesired repercussions.

- If the solution of the model succeed in defining the economic phenomena by applying historical data this may give great push to the suggested approach in answering the questions raised concerning the knowledge generation, specifically the circle pole of causation. If the interpretation of the facts derived by applying the model improved and enhanced our understanding to economic life this can give extra motivations to apply the approach in other fields rather than economics.

- The results of theoretical and practical tests to the model determine the capability of suggested approach in defining and interpreting the phenomenal, hence it can be applied in the process of knowledge generation moreover acquiring of values. In addition, if the application of the approach improve our understanding to the phenomenal this may reduce model imitation and at same time rationalize the use of the opinion of top to bottom way of thought .

- The self-inclination of the dependent variable to specific destination excrete inter-causation between ad hoc and post hoc variables, eventually this may redefine the relationship between them to what proposed as accommodated and accommodator variables.

- We expect that long run trend of income and price level given by the coefficients of the lag 
variables in the model are equal to the equilibrium rates when solving the model (quadratic equation)

- The equilibrium of each sub sector in the model solves by according to the equilibrium values of income and price (top to bottom)

- We expect that the characteristics properties of the model reach by eign values eign vectors eign space consolidate the applications of the model.

- The geometric shape of the aggregate demand and supply equations reveals that how to evaluate the root standing point of each economic school of thought.

- Exchange rate as well as interest rate are predominantly subject to the equilibrium levels og income and price (maximum potency of the economy)

\section{DISCUSSION}

Exogenous theories of growth focus on how to achieve long run growth rate in order to meet sustainable development standards that include the expected growth in labour force and capital. The calculated equilibrium values serve as standing point to achieve the target of maximum potency of the economy. In addition downward moving or top to bottom procedure is crucial I determining the values of sub sectors in a way that expressing how the instruments variable interact to realize the maximum potency of the economy. Here any altering in these values would disturb the equilibrium targets and hence serious cyclical aftermath will prevail. Moreover price, interest as well as exchange rate recommended according to the maximum potency equilibrium play as motivator and appetizers to the instrumental variable in the process of achieving the target equilibrium. Any manipulation to them away from equilibrium roots will disturb the matter instead of stimulating it. The characteristics of the model matrix determine the length of current long run maximum potency, then new investigation to next long run equilibrium must be done to alter ongoing instruments orientation. Finally in the light of geometrical shape of aggregate demand and supply school debates can be managed in favor of accomplishing the maximum potency of the economy and hence maintaining warranted growth rate.

\section{MATERIALS, TOOLS AND PROTOCOL}

Analytical geometry tools i.e straight line equations, quadratic form of equation, conic section equations, in addition to general rule of factorization are necessary materials for explaining the mathematical model of the study. Moreover, matrix algebra materials namely characteristic equation, eign values, eign vectors, egin space are important for examining the nature of the model. Also econometrics methods covering model formation which incorporate dependent and independent variables are necessary for specification, estimating as well as testing the model in order to find numeric values to the parameters via which the equilibrium values of the model can be reached.

To form a protocol for model applications first gathering adequate historical data covering different trade cycles, second proper specification of econometric model including to all macro-economic variables must be established and tested to show the pre required estimation conditions, third appropriate estimator should to be chosen in shed of sound forecast scenario, fourth replacing the estimated values of the parameters in the mathematical form of the suggested model, solving the equilibrium level of income and price, seven going down through the model to determine the values and equilibrium of each sub sector. Eight according to the values of policy instruments design the scenario that achieve the future equilibrium values of income and price which implicitly are the long run trend. 


\section{CONCLUSION}

If the income model above proves its validity in theory and practice, the method of accommodation can introduce proper understanding to the economic phenomenon (income) from the top to bottom. We have to look at the phenomena not from so-called dependent variable but what so called accommodated one. This method leads to the conclusion that the ability of the ad hoc variables to change the path of the phenomenon is limited and conditional and therefore we can rely on the ad hoc and post hoc variables simultaneously for a broader understanding of the economic phenomenon or looking from top to bottom. The final idea is to look at the relationship between the variables through the accommodator and the accommodated rather than the ad hoc and the post hoc by restricting the concept of freedom of the ad hoc variables and converting them into variables supportive to the accommodated variable to reach its destiny.

The hypothesis raised by the study is that it is difficult to direct any phenomena and hence the explanatory variables have limited role in achieving policy targets, so according to the detective results mainly the equilibrium level of income and price which represents the maximum potency that given economy can research, any device policy beyond this level would distort the overall system in addition it may drive to undesired results according to suggested model. As result, significantly, accommodated role to explanatory variables is recommended.

In the practical outlook of the method it can be used to interpret and understand other noneconomic phenomena have contradicting forces in reaching equilibrium. If the method lead to best understanding to the phenomenon, this in turn increases and improves the theoretical and practical capacity of the accommodation method. 


\section{REFERENCES}

[1]Arestis, P., Ferrari Filho, F., \& Terra, F. H. B. (2018). Keynesian macroeconomic policy: Theoretical analysis and empirical evidence. Panoeconomicus, 65(1), 1-20.

[2]Bårdsen, G., Jansen, E. S., Eitrheim, O., \& Nymoen, R. (2005). The econometrics of macroeconomic modelling. Oxford University Press on Demand.

[3] James Gwartney \& Richard Stroup (199) "macroeconomics, private \& public choice- new york 9" p 345 to 355

[4]Bresser-Pereira, L. C. (2012). "Five models of capitalism". Brazilian Journal of Political Economy, vol. 32, n 1 (126), p. 21-32, January-March/2012.

[5]Bresser-Pereira, L. C. (2012). Why economics should be a modest and reasonable science. Journal of Economic Issues, 46(2), 291-302.

[6]Colander, D. (2011). Is the fundamental science of macroeconomics sound?. Review of Radical Political Economics, 43(3), 302-309.

[7]Chari, V. V., Kehoe, P. J., \& McGrattan, E. R. (2009). New Keynesian models: not yet useful for policy analysis. American Economic Journal: Macroeconomics, 1(1), 242-66

[8]Diamond, P. A. (1982). Aggregate demand management in search equilibrium. Journal of political Economy, 90(5), 881-894.

[9]Dopp, A. R., Mundey, P., Beasley, L. O., Silovsky, J. F., \& Eisenberg, D. (2019). Mixed-method approaches to strengthen economic evaluations in implementation research. Implementation Science, 14(1), 2.

[10]Edgmand., R. Michael (1987) “Macroeconomics, theory \& practice"-.p 291 to 327

[11]Eltahir, Y. (2014). Aggregate Demand \& aggregate Supply: Formulating Equations and their Policy Implications. The Journal of American Science, 10(12), 1-6.

[12] El Tahir, Y., \& El Otaibi, D. (2014). Internal Rate of Return: A suggested Alternative Formula and its Macroeconomics Implications. J Am Sci, 10(11), 216-221.

[13]Exlender gray(1951) "depevelopment of economics Dotorine" Natural Press limited P 248 to 266 [14]Halsmayer, V., \& Hoover, K. D. (2016). Solow's Harrod: Transforming macroeconomic dynamics into a model of long-run growth. The European Journal of the History of Economic Thought, 23(4), 561-596.

[15]Inprage Hne Rima (1986) “Development of economic Analysis” fourth edition-Homewood P 450 to 473

[16]Palma, G. (2005). Four sources of de-industrialisation and a new concept of the Dutch Disease. Beyond reforms: structural dynamics and macroeconomic vulnerability, 3(5), 71-116.

[17]Keynes, John Maynard (1980) Activities 1940-46: Shaping the Post World: Employment and Commodities, in Collected Writings, vol. XIII. London: Macmillan. Quoted by Luiz Fernando de Paula (2008).

[18]Rosolind Levacic (1982) "the static \& dynamic analysis" -the Macmillan press ltd,. P 9. to 363

[19]Sherstnev, M. A. (2019). World Economy, Economic Science, and Economic Policy: What Comes After the Crisis. In Sustainable Growth and Development of Economic Systems(pp. 87-100). Springer, Cham.

[20]Spadoni, C. (1986). Who Wrote Bertrand Russell's" Wisdom of the West?". The Papers of the Bibliographical Society of America, 80(3), 349-367

[21]Zellner, A., \& Arnold, Z. (2004). Statistics, econometrics and forecasting. Cambridge University Press

[22]Chiange, C. A.( 2005), "Fundamental Methods of Mathematical Economics" - 4th edition- Mc craw hill $\mathrm{P} 444$ to 475 